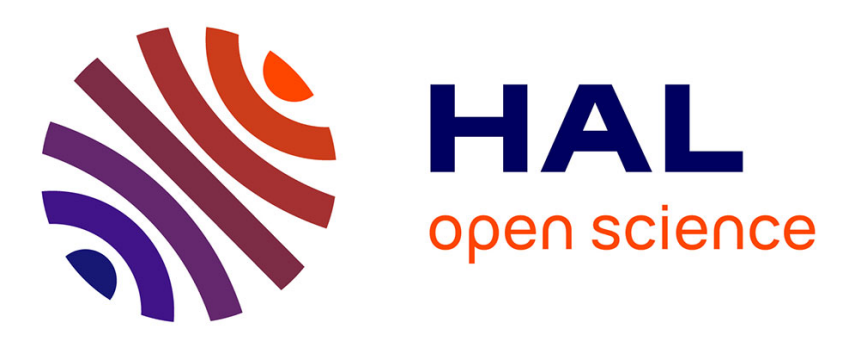

\title{
Cultivar-dependent partial resistance and associated defence mechanisms in wheat against Zymoseptoria tritici
}

M. Ors, B. Randoux, Sameh Selim, A. Siah, G. Couleaud, C. Maumené, K. Sahmer, P. Halama, P. Reignault

\section{To cite this version:}

M. Ors, B. Randoux, Sameh Selim, A. Siah, G. Couleaud, et al.. Cultivar-dependent partial resistance and associated defence mechanisms in wheat against Zymoseptoria tritici. Plant Pathology, 2018, 67 (3), pp.561-572. 10.1111/ppa.12760 . hal-02948134

\section{HAL Id: hal-02948134 \\ https://hal.science/hal-02948134}

Submitted on 28 May 2021

HAL is a multi-disciplinary open access archive for the deposit and dissemination of scientific research documents, whether they are published or not. The documents may come from teaching and research institutions in France or abroad, or from public or private research centers.
L'archive ouverte pluridisciplinaire HAL, est destinée au dépôt et à la diffusion de documents scientifiques de niveau recherche, publiés ou non, émanant des établissements d'enseignement et de recherche français ou étrangers, des laboratoires publics ou privés. 
Cultivar-dependent partial resistance and associated defense mechanisms in wheat against Zymoseptoria tritici

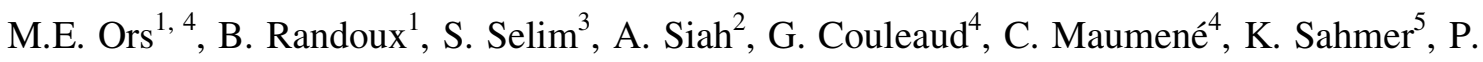
Halama $^{2}$ and Ph. Reignault ${ }^{1 *}$

${ }^{1}$ Univ. Littoral Côte d'Opale, UCEIV-EA 4492, Unité de Chimie Environnementale et Interactions sur le Vivant, SFR Condorcet FR CNRS 3417, F-62228, Calais cedex, France.

2 Laboratoire Charles Violette, SFR Condorcet FR CNRS 3417, Institut Supérieur d'Agriculture, 48 Boulevard Vauban, F-59046 Lille cedex, France.

${ }^{3}$ UniLaSalle, Department of Agronomy and Animal Science, SFR Condorcet FR CNRS 3417, BP 30313, F-60026 Beauvais cedex, France.

${ }^{4}$ Arvalis-Institut du Végétal, Station expérimentale de Boigneville, F-91720 Boigneville, France.

${ }^{5}$ Laboratoire Génie Civil et géoEnvironnement (LGCgE) Lille-Nord de France, Institut Supérieur d'Agriculture, 48 Boulevard Vauban, 59046 Lille Cedex, France.

*philippe.reignault@univ-littoral.fr

Running Head : Wheat partial resistance to Zymoseptoria tritici 
Key words: Triticum aestivum L., Zymoseptoria tritici, defense mechanisms, RT-qPCR, cell wall degrading enzymes.

\section{Abstract.}

Septoria tritici blotch caused by the fungus Zymoseptoria tritici is one of the most devastating foliar diseases of wheat. Knowledge regarding mechanisms involved in resistance against this disease is required to breed durable resistances. We compared here the expression of defense and pathogenicity determinants in three cultivars in semi-controlled culture conditions. The most susceptible cultivar, Alixan, presented higher necrosis and pycnidia density levels than Altigo, the most resistant one. In Premio, a moderately resistant cultivar, necrosis developed as in Alixan, while pycnidia developed as in Altigo. In non-infectious conditions, genes encoding for PR1 ( $p r l)$, glucanase ( $g l u c)$ and allene oxide synthase (aos) were constitutively expressed at a higher level in both Altigo and Premio than in Alixan, while chitinase2 (chit2), phenylalanine ammonia lyase (pal), peroxidase (pox2) and oxalate oxidase (oxo), were expressed at a higher level in Premio only. Except for aos, all genes were induced in Alixan during the first steps of the infection symptomless phase. Only pox2, oxo, gluc and pal and pal, chs and lox genes were up-regulated at some time points in Altigo and Premio, respectively. Basal cultivar-dependent resistance against $Z$. tritici could therefore be explained by various genes expression patterns than high expression levels of given genes. During the necrotrophic phase, Z. tritici cell-wall degrading enzyme activity levels were lower in Altigo and Premio than in Alixan, and were associated more with pycnidia than with necrosis. Similar tissue colonization occurred in the three cultivars, suggesting an inhibition of the switch to the necrotrophic lifestyle in Altigo. 


\section{Introduction.}

Septoria tritici blotch (STB) is one of the most devastating foliar diseases of wheat (Triticum aestivum L.) and is caused by the hemibiotrophic fungus Zymoseptoria tritici (telemorph: Mycosphaerella graminicola), previously known as Septoria tritici. The Z. tritici infection process is characterized by a latent period of approximately 10-15 days during which fungal germ tube grows on the leaf surface, penetrates either through the stomatal opening or directly via the epidermal cell wall, and colonizes the intercellular space between mesophyll cells (Cohen and Eyal, 1993; Duncan and Howard, 2000; Kema et al., 1996; Siah et al., 2010). The fungus then rapidly switches to necrotrophic growth, associated to an increase of the fungal biomass, chlorotic and/or necrotic lesions on the leaf surface, and the formation of pycnidia in colonized substomatal cavities. Although no haustoria are differentiated, Z. tritici obtains nutrients from the plant apoplastic space during the biotrophic period, whereas during the necrotrophic and symptomatic phase, the fungus releases cell wall degrading enzymes (CWDEs) leading to an increase of nutrient content in this apoplastic space (Keon et al., 2005; Siah et al., 2010). The production of cell-wall degrading enzyme (CWDEs), such as $\beta$ 1,4-endoxylanase, by $Z$. tritici has been correlated with symptom and sporulation levels (Douaiher et al., 2007; Siah et al., 2010). In their study, Tian et al. (2009) showed that $\beta-1,4-$ endoxylanase and protease activities are highly associated with the susceptibility level of the infected wheat cultivar. Although carbohydrate degrading enzymes (CAZymes)-encoding genes are more frequently observed in the genomes of necrotrophic fungi, the Z. tritici genome possesses more genes coding for proteases than for CAZymes (Goodwin et al., 2011).

The control of STB in the field mainly relies on the use of conventional fungicides. However, their use is increasingly controversial because of their impact on both the environment and human health. In addition, their efficacy is compromised in the field because of the 
development and widespread of fungicide-resistant Z. tritici strains. An alternative to chemical control is breeding for new and more resistant wheat cultivars. However, such a strategy requires better knowledge of wheat defense mechanisms against STB.

Wheat resistance against Z. tritici can be controlled either by specific or non-specific partialresistance. The first one confers a complete resistance, observed during incompatible interactions, and is controlled by gene-for-gene relationships (Brading et al., 2002). To date, 18 specific stb $R$ genes have been identified in wheat against $Z$. tritici, which should be capitalized in order to obtain a durable resistance (Brading et al., 2002; Simón et al., 2012). On the other hand, partial resistance or quantitative disease resistance (QDR) is observed during compatible interactions. It is not isolate-specific and is controlled by several genes or by quantitative traits loci (QTL) (Chartrain et al., 2004). In this case, severity of symptoms caused by different strains of $Z$. tritici varies between wheat cultivars, leading to a wide range of susceptibility/resistance levels. It has been reported that Z. tritici populations can overcome specific resistances, which are less durable than QDR in the field. Breeding for several selected genes or loci involved in QDR can also lead to an increased durability of wheat resistance against STB in the field (Chartrain et al., 2004; Orton et al., 2011).

Wheat defense mechanisms against $Z$. tritici have been recently investigated by molecular and biochemical studies in order to identify host responses, but previous works focused on incompatibles interactions, with compatibles ones studied only as a reference. It has been suggested that pathogenesis-related (PR) proteins, reactive oxygen species (ROS) metabolism, cell wall reinforcement with callose, and signalling via the MAPK pathway are involved in wheat resistance against STB (Adhikari et al., 2007; Diani et al., 2009; Fazeli and Jelodar, 2012; Rudd et al., 2008; Shetty et al., 2003, 2007, 2009; Yang et al., 2013). Indeed, 
most of studied defense-related genes were differentially expressed between compatible and incompatible interactions. Early expression, before penetration, of host genes encoding for PR1, chitinases, glucanases and peroxidases was suggested to contribute to wheat resistance during incompatible interactions (Adhikari et al., 2007; Yang et al., 2013). In STB resistant cultivars, no evidence of hypersensitive response (HR) was observed during the first steps of the infectious process (Kema et al., 1996), while HR occurs early on plants during incompatible interactions with other biotrophic pathogens, and refers to effector-triggered immunity (ETI) (Jones and Dangl, 2006). However, during the fungal switch from the biotrophic to the necrotrophic phase, necrosis consisting of a programmed cell death (PCD) showing similarities with HR was observed in susceptible wheat cultivars (Keon et al., 2007). It has been suggested that in susceptible and only partially resistant cultivars, Z. tritici undergoes adaptation to wheat defence metabolites and manipulates defense mechanisms during its extracellular infection process (Keon et al., 2007; Hammond-Kosack and Rudd, 2008; Rudd et al., 2008). However, very little is known so far about the features of wheat defences expressed during compatible interactions and QDR leading to partial resistance.

In the present study, we therefore investigated wheat QDR expressed during compatible interactions with Z. tritici. We compared the expression of defence markers associated with this partial resistance in three distinct wheat cultivars characterized in the field by various resistance levels to STB. First, infection process and fungal pathogenicity were examined by cytological and biochemical approaches during both biotrophic and necrotrophic phases of the infection. Furthermore, wheat defenses were studied by molecular and biochemical tools during the early period following leaf inoculation. We measured by quantitative real-time PCR (RT-qPCR) the expression level of a set of genes involved in wheat defense activated either during specific resistance, after pathogen infection or resistance inducer treatment. The 
expression of chitinase 2- and glucanase-encoding genes (AB029935; DQ090946) was induced in cultivars resistant to Z. tritici. (Adhikari et al., 2007; Shetty et al., 2009), while the expression of pathogenesis-related protein 1 (PR1) encoding gene (HQ 848391) was induced earlier and with a higher level during an incompatible interaction between wheat and Puccinia triticina than in compatible interactions (Gao et al., 2015). The expression of a lipoxygenase-encoding gene (U32428) was also studied according to the induction observed after Benzothiadiazole (BTH; Gorlach et al, 1996) and trehalose (Tayeh et al., 2014) preventive treatments, which protected wheat against Blumeria graminis f. sp. tritici. The peroxidase (POX2) encoding gene (X85228) and the phenylalanine ammonia lyase (PAL) encoding gene (AY005474) were expressed in wheat leaves infected by Blumeria graminis f. sp. tritici (Båga et al., 1995; Tayeh et al., 2015). Expression of the chalcone synthase (CHS) gene (AY286097), encoding for a key enzyme involved in phenylpropanoid pathway, was partially reduced after inoculation by Z.tritici in both resistant and susceptible cultivars (Shetty et al., 2009). Likewise, the expression of the oxalate oxidase (OXO) encoding gene (AJ556991) was not induced by treatment by glucan extract from Z.tritici (Shetty et al. 2009). The allene oxide synthase (AOS) gene (AY196004.1) encoding the first enzyme after LOX in the octadecanoid pathway, was isolated from wheat (Wu et al., 2004). The involvement of these defense mechanisms in the expression of the non-specific wheat resistances studied here against $Z$. tritici is discussed.

\section{Experimental procedures}

\section{Plant and fungal growths and pathogenicity tests}

Cultivars exhibiting distinct levels of partial resistance or susceptibility, i.e. Alixan, Premio and Altigo, were selected, with resistance notes of 4, 5.5 and 7, respectively, on a scale from 0 (fully susceptible) to 9 (fully resistant) at the field level (Arvalis info, 2009). Resistance notes were obtained after two years of field trials performed by GEVES (Groupe d'Etudes des 
Variétés et Semences), the French organism officially involved in cultivar characterization before they are released on the market. Symptom intensities were assessed at several developpemental stages and statistically validated for both individual and pooled trials. Postregistration resistance traits of cultivars were then monitored for two additional years for their stability at the field level by Arvalis-Institut du Végétal, the French Technical Institute dedicated to cereals.

Wheat grains were germinated in Petri dishes on moist filter paper in darkness at $20{ }^{\circ} \mathrm{C}$ for 24 $\mathrm{h}$, at $4{ }^{\circ} \mathrm{C}$ for $48 \mathrm{~h}$ and then at $20{ }^{\circ} \mathrm{C}$ for $24 \mathrm{~h}$, and 12 germinated grains were then placed into pots filled with $3 \mathrm{~L}$ loam in the greenhouse at $18{ }^{\circ} \mathrm{C}\left( \pm 2^{\circ} \mathrm{C}\right)$ with a $16 / 8 \mathrm{~h}$ photoperiod with supplementary illumination. After 3 weeks (when the third leaf from the base of the plant was fully expanded), plants of each pot were inoculated using hand sprayer with $30 \mathrm{~mL}$ of spore suspension in distillated water $\left(10^{6}\right.$ spores. $\left.\mathrm{mL}^{-1}\right)$ amended with $0.05 \%$ polyoxyethylenesorbitan monolaurate (Tween 20, Sigma). Control plants were treated with sterile distillated water containing Tween20. Immediately after inoculation, each pot was covered with a clear polyethylene bag for 3 days in order to ensure a water-saturated atmosphere compatible with a good fungal germination. The disease level was scored at 21 days after inoculation (dai) by noting the percentage of the third leaf area with symptoms (chlorosis and necrosis) and by noting their pycnidial density on a scale from 0 (absence of pycnidia) to $5(1,2,3,4,5$ correspond to less than $20 \%, 20-40 \%, 40-60 \%, 60-80 \%$, and $80-100 \%$ of leaf areas bearing pycnidia, respectively)). 


\section{Histopathological analysis}

Monitoring of spore germination and leaf penetration by Z. tritici was performed using Fluorescence Brightener 28 (Calcofluor, Sigma) according to Siah et al. (2010). Segments (2 $\mathrm{cm}$ ) were harvested from the third fully expanded leaf at 1 and 5 dai from inoculated plants and then immersed for $5 \mathrm{~min}$ in a solution of $0.1 \%(\mathrm{w} / \mathrm{v})$ Calcofluor in $0.1 \mathrm{M}$ Tris- $\mathrm{HCl}$ buffer $\mathrm{pH}$ 8.5. Leaf segments were washed for $2 \mathrm{~min}$ with sterile distillated water. After drying, they were placed on a glass slide, covered with a cover slip and observed microscopically (Nikon, Eclipse 80i) under UV illumination. Mesophyll colonization was investigated using Trypan blue (Shetty et al. 2003; Siah et al. 2010) with few modifications. Leaf segments $(2 \mathrm{~cm})$ were harvested from both control and inoculated leaves and cleared in a mixture of absolute ethanol: glacial acetic acid (3: 1, v/v) overnight. Cleared leaves were rehydrated for $4 \mathrm{~h}$ in distilled water and then fixed for $20 \mathrm{~min}$ in lactoglycerol (lactic acid: glycerol: water, 1: 1: 1, v/v / v). Staining of the fungus was carried out at $70{ }^{\circ} \mathrm{C}$ by immersing the leaf segments in $0.1 \%$ Trypan blue dissolved in lactophenol-ethanol $(1: 2, \mathrm{v} /$ v) for $6 \mathrm{~h}$. After washing, leaf segments were stored in lactoglycerol, placed on a glass slide, covered with a cover slip and then observed microscopically under white light illumination. Spores were recorded for each cultivar on three leaf segments and subsequently 150 randomly chosen spores were studied. Two independent experiments were performed. The percentage of germinating spores (GS) was recorded at 1dai. Total germinated spores with penetrated germ tube (PS) and within PS, penetrations through stomata (PSS) were accounted at 5 dai. At 21 dai, total colonized substomatal cavities (CS) among 150 randomly chosen cavities were recorded and, within CS, percentages of colonized substomatal cavities bearing pycnidia (CSP) were estimated according to the microscopic notations reported by Siah et al. (2010). 


\section{Protein extraction and enzymatic assays}

\section{CWDE and protease assays.}

Total protein extractions were carried out at 1, 5, 11, 17 and 21 dai as previously described by Magro et al. (1984) and Siah et al. (2010) with few modifications. Briefly, $5 \mathrm{~g}$ of inoculated and control third leaves were removed and immediately frozen in liquid nitrogen prior to grinding in a mortar. The resulting powder was then dispersed in $5 \mathrm{~mL} 0.05 \mathrm{M}$ Tris- $\mathrm{HCl}$ buffer $\mathrm{pH} 7.8$ containing $0.1 \mathrm{M} \mathrm{KCl}$ and $0.5 \%$ cysteine. After cooling for $30 \mathrm{~min}$ at $4{ }^{\circ} \mathrm{C}$, the mixture was squeezed through three layers of cheesecloth and centrifuged at $13000 \mathrm{~g}$ for 20 min at $4{ }^{\circ} \mathrm{C}$. From the supernatant, $100 \mu \mathrm{L}$ were transferred to an Eppendorf tube and stored at $4^{\circ} \mathrm{C}$ for total protein quantification. Total protein extracts were then dialyzed against $0.5 \mathrm{~L}$ of distilled water for $24 \mathrm{~h}$ at $4{ }^{\circ} \mathrm{C}$ overnight (SpectrumLab Inc.). The dialyzed solution was then subjected immediately to $\beta-1,4$-endoglucanase and $\beta-1,4$-endoxylanase activity quantification using a modified 3,5-dinitrosalicylic acid (DNS) method (Douaiher et al., 2007; Siah et al., 2010). Absorbance was measured at $540 \mathrm{~nm}$. Protease activity was measured according to the protocol described by Hellweg (2003) with slight modifications. Six aliquots of $100 \mu \mathrm{L}$ of total protein were heated to $80{ }^{\circ} \mathrm{C}$ for 10 min to inactivate enzyme activity. After cooling, $50 \mu \mathrm{L}$ of azocasein solution (20 mg/mL Azocasein, SIGMA) and 50 $\mu \mathrm{L}$ of incubation buffer (200 mM Tris, $20 \mathrm{mM} \mathrm{CaCl}_{2} \mathrm{pH}$ 7.8) were added. After incubation at $40{ }^{\circ} \mathrm{C}$ under gentle agitation for 30 to $60 \mathrm{~min}, 500 \mu \mathrm{L}$ of $5 \%$ aqueous trichloroacetic acid were added to precipitate non-digested protein and the mixture was incubated for $10 \mathrm{~min}$ at room temperature. The precipitate was pelleted by centrifuging for $5 \mathrm{~min}$ at $13000 \mathrm{~g}$ and 500 $\mu \mathrm{L}$ of test buffer were added at $400 \mu \mathrm{L}$ of the supernatant. Absorbance was measured at 400 $\mathrm{nm}$. Total protein concentrations were determined at $595 \mathrm{~nm}$ using bovine serum albumin as a standard (Bradford, 1976). 


\section{RNA extraction and gene expression relative quantification by real-time RT-qPCR}

Wheat leaves were sampled at 3, 6, 12, 24, 72 and 96 hours after inoculation (hai) with $Z$. tritici. The same sampling procedure was also conducted in non-inoculated conditions. All samples were immediately frozen and stored at $-80{ }^{\circ} \mathrm{C}$ until use. Total RNA was extracted from $80 \mathrm{mg}$ of plant tissue using RNeasy Plant Mini Kit (Qiagen, The Netherlands). Reverse transcription of total RNA was carried out using QuantiTect ${ }^{\circledR}$ Reverse Transcription Kit (Qiagen, USA) according to the manufacturer's protocol. Real-time qPCR was performed using ABI Prism 7300 detection system (Applied Biosystems, USA). Table 1 describes primer pairs designed using the Primer Express ${ }^{\circledR}$ program and tested for secondary structure using the AmplifX ${ }^{\circledR}$ program. A set of 9 genes was tested: prl (HQ 848391), chit2 (AB029935), gluc (DQ090946), lox (U32428), aos (AY196004.1), pal (AY005474), chs (AY286097), pox2 (X85228) and oxo (AJ556991) encoding PR1, chitinase, glucanase, lipoxygenase, allene oxide synthase, phenylalanine ammonia lyase, chalcone synthase, peroxidase and oxalate oxidase respectively. The tub6 (accession number U76897) and GAPDH (accession number AF251217) genes were used as housekeeping genes (Scholtz and Visser, 2013). Cycling conditions consisted of a denaturation cycle ( $95{ }^{\circ} \mathrm{C}$ for $3 \mathrm{~min}$ ) and an amplification and quantification cycle repeated 40 times $\left(95^{\circ} \mathrm{C}\right.$ for $3 \mathrm{~s}, 60{ }^{\circ} \mathrm{C}$ for $\left.30 \mathrm{~s}\right)$. Expression ratios for each cDNA were calculated for each time point, relative to control at the same time using the $2^{-\Delta \Delta \mathrm{Ct}}$ described by Livak and Schmittgen (2001), where $\Delta \Delta \mathrm{Ct}=[\mathrm{Ct}$ Target (Sample) - Ct Reference (Sample)] - [Ct Target (Control) - Ct Reference (Control)] and $\mathrm{Ct}$ Reference $=$ geometrical mean $(\mathrm{Ct}$ GAPDH : Ct Tub6). Similar amplification efficacies ranging between 90 and $110 \%$ were checked for all the tested primers and expressions ratio values of 2 were considered as a minimum to be significantly different from the (nI) control. The expression level of target gene in control sample sprayed with water 
amended with $0,05 \%$ of Tween 20 was used for relative expression and was given the value of 1.

\section{Statistical analysis}

Data from studies of disease scoring, infection process and enzyme activities were analyzed using ANOVA (Tukey test at $P \leq 0.05$ ) assuming a normal distribution. When necessary, variances were stabilized with logarithmic transformation of data. Values correspond to the average of results obtained in two distinct experiments, on 20 and 3 leaves for disease level and infection process, respectively, and 3 measures for enzyme activity assays. Possible interaction between the two biological experiments and data was verified and no experiment in this study presented significant interaction. For gene expression studies, values correspond to the average of data from three technical repetitions from 2 biological samples. Statistical analyses were carried out with the statistical program Xlstat (Addinsoft, Paris, France). Significant differences were evaluated using the Tukey test at $P \leq 0.05$.

\section{Results}

\section{Disease levels in Alixan, Premio and Altigo}

In order to evaluate their resistance levels, the three cultivars Alixan, Premio and Altigo were inoculated with the T01193 Z. tritici strain and disease severity was assessed at 21 dai on the third leaf (Figure 1). Percentages of leaf area with symptoms recorded in Alixan (41.7\%) and in Premio (42.5\%) were significantly higher than in Altigo (27.7\%). In Alixan, the pycnidial density (2.9) was significantly higher than in Premio (1.1) and Altigo (1.1). 


\section{Infectious process}

Five cytological parameters related to the development of $Z$. tritici were quantified in Alixan, Premio and Altigo at various time points. Table 2 shows percentages of germinated spores (GS) at 1 dai, percentages of total germinated spores with penetrating germ tube (PS) and penetrations through stomata (PSS) at 5 dai, and at 21 dai, the percentage of total colonized substomatal cavities (CS) and within CS, the percentage of CS bearing pycnidia (CSP). Alixan, Premio and Altigo cultivars presented close and non-significantly different percentages of GS at 1dai. At 5 dai, percentages of PS were significantly higher in Alixan and Premio (52.9\% and $55.2 \%$ ) than in Altigo (29.3\%). However, no significant differences were recorded for the percentages of PSS and no significant differences were obtained for the percentage of direct penetration attempts through the epidermis (data not shown). The percentage of CS recorded at 21 dai presented no significant difference between Alixan, Premio and Altigo, while the percentages of CSP recorded in Alixan (19.4\%) and Premio $(23.9 \%)$ were significantly higher than in Altigo (5.2\%).

\section{CWDEs activities}

$\beta$-1,4-endoxylanase, $\beta$-1,4-endoglucanase and protease activities were monitored in leaves during the infection process at 1, 5, 11, 17 and 21 dai (Figure 2). At 1, 5 and 11 dai, these three enzymes showed weak activity levels which were not significantly different from those obtained in non-inoculated control plants for each cultivar.

In Alixan, all enzymatic activities increased significantly in inoculated plants from 17 dai. At 21 dai, they reached higher values than those measured in non-inoculated plants (17 fold, 7 fold and 72 fold higher for $\beta$-1,4-endoxylanase, $\beta$-1,4-endoglucanase and protease, 
respectively). In Premio, $\beta$-1,4-endoxylanase and $\beta$-1,4-endoglucanase significantly increased by 17 dai, while protease activity was induced at 21 dai only. In Altigo, all activities were not modified in inoculated plants at 17 dai, but were produced at 21 dai.

The comparison between inoculated cultivars at 21 dai showed that values obtained in Alixan were 4.5 and 7.2 fold higher for $\beta$-1,4-endoxylanase than those obtained in Premio and Altigo respectively, 3.4 and 4.1 fold higher for $\beta$-1,4-endoglucanase and 3.7 and 5.2 fold higher for protease. Activities measured in Premio and Altigo were not significantly different, excepted for $\beta$-1,4-endoxylanase which was 1.6 fold higher in Premio.

\section{Induction of wheat defense mechanisms by $Z$. tritici}

\section{Basal expression levels of defense-related genes in the three cultivars.}

We established basal transcript profiles of a set of nine distinct genes associated with four types of wheat defenses: ROS metabolism (pox2, oxo), octadecanoid (lox, aos), phenylpropanoid (pal, chs) pathways and PR proteins biosynthesis (prl, chit2, gluc) (Table 3). For a meaningful biological approach, significantly differentially expressed transcripts were reported according to a strict selection criterion; namely, $\mathrm{a} \geq 2.0$-fold change threshold. Gene expression profiles in non-inoculated (nI) plants of Premio and Altigo were compared with Alixan (nI) controls. The basal levels of prl, gluc and aos genes in both Premio and Altigo were significantly higher than in Alixan (approximately 10, 10 and 4-fold respectively), whereas those of chit2, pal, pox2 and oxo were significantly higher in Premio than in both Alixan and Altigo (approximately 2, 3, 2 and 5-fold compared to Alixan, respectively). On the other hand, concerning chs, the basal transcription level recorded in both Premio and in Altigo was lower than in Alixan (approximately 0.6-fold). 


\section{Induction of defense-related genes by $Z$. tritici in Alixan, Premio and Altigo.}

Transcript profiles in inoculated (I) plants of each cultivar were followed at 3, 6, 12, 24, 72 and 96 hai and were compared to their respective (nI) controls, and between (I) Alixan, Premio and Altigo plants (Figures 3, 4, 5 and 6). For a meaningful biological approach, significantly differentially expressed transcripts were reported according to a strict selection criterion; namely, $\mathrm{a} \geq 2.0$-fold change threshold.

Concerning ROS metabolism, the pox2 gene was induced in the Alixan cultivar all over the time course, except at 12 hai (Figure 3). This induction ranged from 7.4- to 24.8-fold compared to the (nI) control. On the other hand, the pox 2 expression was induced at 3,12 and 24 hai in Premio (from 6.6- to 16.9-fold) and at 12 hai only in Altigo (11.3-fold). Moreover, pox2 expression was significantly higher in Alixan compared to both Premio and Altigo at 6, 24, 72 and 96 hai. Likewise, the oxo gene expression was induced in Alixan at 6, 24 and 72 hai (from 3.8- to 6.4-fold), whereas in Premio, it increased from 12 to 72 hai (from 3.1- to 29.9-fold) and in Altigo at 6 and 24 hai (3.3- and 4.5-fold). The highest expression level of oxo gene was measured in Premio 12 hai.

Regarding the octadecanoid pathway, Premio showed an early induction of lox expression at 3 and 6 hai, 2.4- and 7- fold compared to the (nI) control (Figure 4). This gene expression was induced later in Alixan (2.4-fold 72 hai), and no up-regulation was observed in Altigo. In addition, the lox expression exhibited down regulations in Alixan 12 hai, and 24 hai in the three wheat cultivars. The aos gene expression was only induced in Premio 72 hai (2.7-fold), while it was down regulated in Premio and Altigo 24 hai, and in Alixan and Premio 96 hai.

Concerning the phenylpropanoid pathway, an induction of the pal gene expression was observed in Premio at 3,6 and 12 hai from 3- to 16.6-fold compared to the (nI) control (Figure 5). On the other hand, the pal expression was induced later at 6 and 72 hai in Alixan 
(5.6-fold) and at 3 hai only in Altigo (4.5-fold). Regarding the chs gene, Premio showed an early induction of expression 12 hai (10.4-fold) and this gene was induced later in Alixan, at 96 hai (4.5-fold), but not in Altigo. The chs expression exhibited a down-regulation in Alixan 12 hai, and in Alixan and Altigo 24 hai. Moreover, the highest expression levels of both pal and chs genes were measured in Premio (16.6- and 10.4-fold, respectively) at 12 hai.

Concerning the PR-proteins, the prl gene expression in Alixan showed an induction all over the time course except at 6 and 12 hai, which ranged from 7.9- to 21.8 -fold compared to the (nI) control (Figure 6). In Premio, this gene expression was induced at 6 and 96 hai, from 5.3to 6.2-fold, and no significant induction was observed in Altigo. Moreover, the prl expression level was significantly higher in Alixan than in both Premio and Altigo at 3, 24, 72 and 96 hai. Similarly, the chit 2 gene expression was significantly induced in Alixan all over the time course, except at 6 and 12 hai, and the most drastic inductions were measured at 3 and 24 hai (10.1- and 38.1-fold, respectively). In Premio, this gene expression was slightly induced at 12 and 72 hai (from 3.9- to 4.1-fold) and no significant induction was observed in Altigo. The expression level of the gluc gene increased in Premio at 6 hai, in Altigo at 12 hai and in Alixan at 24 hai (7.4, 2.6 and 2.4-fold, respectively).

\section{Discussion.}

Wheat non-specific resistance expressed during a compatible interaction with Z. tritici is more durable, but harder to select and much less studied than specific resistance (Chartrain et al., 2004b; Orton et al., 2011). Three wheat cultivars (susceptible, moderately and partially resistant) have been compared in the present study in order to characterize mechanisms involved in such a resistance against $Z$. tritici. 


\section{Defense mechanism expression during compatible interaction varies depending on the}

wheat cultivar

In literature, studies often refer to comparisons between compatible and incompatible interactions, in order to highlight mechanisms involved in wheat specific resistance against $Z$. tritici. Molecular studies described in resistant cultivars an early up-regulation of defenserelated genes, e.g. those encoding for phenylalanine ammonia-lyase, peroxidase, chitinase, and various other pathogenesis-related (PR) proteins such as PR-1, PR-2 (for $\beta-1,3-$ endoglucanase), and PR-5 (for thaumatin-like protein). On the other hand, little or no induction of these genes was observed in susceptible cultivars during the first days after infection (Shetty et al., 2003; Ray et al., 2003; Adhikari et al., 2007). Recently, a transcriptome analysis during a compatible interaction revealed that many wheat genes related to defense responses were down-regulated 1 day after leaf inoculation with $Z$. tritici (Rudd et al., 2015). In our study, although Altigo is more resistant than both other studied cultivars, most of targeted genes were not induced or were repressed in this cultivar during the first 24 hours after infection, except for $g l u c$, oxo, pox 2 and pal genes at rare time points, By contrast, high levels of induction were observed in Alixan during the same period of time and until 4 dai, especially for pox2, chit 2 , and $P R 1$, while this cultivar was the most susceptible cultivar among the three studied one. Similarly, in the transcriptomic study of a compatible Z. tritici-wheat interaction, Yang et al. (2013) noticed an up-regulation at 4 dai of some defense genes such as $P R 2, P R 3$ (chitinase) and genes involved in ROS metabolism. Interestingly, in Premio, PR1, chit2, oxo and pox2 were moderately induced compared to Alixan. In Premio, the necrosis development recalled that observed in Alixan, while sporulation is reduced like in Altigo. Moreover, the percentages of direct penetration attempts through the epidermal cell wall were higher in Alixan and Premio. In various studies, the penetration of Z. tritici via stomata was described as more frequent than direct penetration 
through the epidermis (Kema et al., 1996; Shetty et al., 2003; Selim et al., 2013). In Alixan and Premio, the direct penetration attempts may be responsible for the higher defense gene expression observed during the first hours after infection.

However, despite a stronger induction of genes usually involved in PTI, Alixan exhibited an important infection rate. In this cultivar, potential effectors released by the fungus could block or suppress the resulting induced defense, therefore facilitating fungal growth during the biotrophic phase and leading to subsequent important diseases lesions, as suggested by Yang et al. (2013) and Rudd et al. (2015). Apoplastic fungi such as Z. tritici are known to overcome basal plant induced defense involved in PTI by defensive strategies, for instance by releasing chitin binding effectors (Stotz et al., 2014). Indeed, during its endophytic phase of colonization, Z. tritici produces the Mg1LysM and Mg3LysM effectors, which bind chitin and protect hyphae against plant chitinases (Marshall et al., 2011). Mg3LysM-encoding gene was shown to be up-regulated from 1 day after infection in a susceptible cultivar (Rudd et al, 2015). In addition, this effector blocks the elicitation of chitin-induced plant defenses mediated by both chitin elicitor binding protein $(\mathrm{CEBiP})$ and chitin elicitor receptor kinase (CERK) in wheat (Lee et al., 2014; Marshall et al., 2011). In Alixan, a first induction of chit2 was observed at 3 hai, followed by a stronger one at 24 hai. In summary, Z. tritici probably overcomes defenses mediated by chitin release during the fungal cell wall degradation by wheat chitinases, mainly from 1 dai in such a susceptible cultivar.

ROS accumulation is considered as one of the major primary responses during the Z. triticiwheat interaction. However, these compounds are known to accumulate during the necrotrophic phase in compatible interactions, while their synthesis occurs earlier during incompatible interactions. The accumulation of hydrogen peroxide $\left(\mathrm{H}_{2} \mathrm{O}_{2}\right)$ is thought to arrest wheat penetration by biotrophic fungi and to inhibit colonization by Z. tritici in resistant cultivars (Shetty et al., 2003, 2007). In the three studied susceptible cultivars and mainly in 
Alixan, both oxo and pox 2 expressions were induced after infection. Oxalate oxidase produces $\mathrm{H}_{2} \mathrm{O}_{2}$ by the conversion of oxalic acid and $\mathrm{O}_{2}$ (Bolwell and Wojtaszek, 1997) and is considered as a marker of pathogen infection in powdery mildew-cereal interactions. Our results suggest that this enzyme may be involved in the $Z$. tritici-wheat interaction as well. However, since peroxidases use $\mathrm{H}_{2} \mathrm{O}_{2}$ as a substrate during defense responses (O'Brien et al., 2012; Passardi et al., 2005; Torres and Dangl, 2005), the up-regulation of pox2 suggests that $\mathrm{H}_{2} \mathrm{O}_{2}$ does not accumulate. Interestingly, the stronger and long-lasting induction of pox2 in the most susceptible cultivar Alixan indicates that such up-regulations may be considered as a physiological reaction to infection rather than an efficient defense reaction. This gene induction was previously described in wheat in response to powdery mildew infection (Båga et al., 1995).

On the contrary, pal expression was induced from 3 hai untill 12 hai in Premio, and was followed by an induction of chs at 12 hai, suggesting a potential synthesis of flavonoids in this cultivar. Resistance-related metabolites belonging to the flavonoids chemical class were recently identified in barley in response to Fusarium graminearum (Bollina et al., 2011). In Alixan, a slight biphasic induction of pal occurred (at 6 and 72 hai), while a 4-fold induction of pal was observed in Altigo 3 hai. Comparing wheat cultivars, Adhikari et al. (2007) showed that a pal gene was induced during the first hours after infection by Z. tritici in a fully resistant cultivar, while its induction was less significant in a distinct other one and undetected in susceptible cultivars. The phenylpropanoid pathway may therefore be involved in PTI in wheat against Z. tritici in a cultivar-dependant manner. By contrast, the octadecanoid pathway is either slightly stimulated or even repressed, during the first steps of the interactions studied here. Acting upstream of the octadecanoid pathway, the lipoxygenase activity catalyses the dioxygenation of polyunsaturated fatty acid and leads, when followed by alene oxide synthase encoded by aos gene, to the downstream biosynthesis of jasmonic 
acid (JA) (Creelman and Mullet, 1997). In Alixan and Altigo cultivars, lox gene has not been up-regulated in the first hours after infection, and its expression was repressed at 12 and 24 hai in both cultivars. In Premio, a similar repression was observed at 24 hai, after an induction at 3 and 6 hai, recalling results obtained in a fully resistant cultivar by Ray et al. (2003). Similarly, aos was repressed at 24 hai in Premio and Altigo. Besides, Rudd (2015) described a down regulation 1 dai of five genes noted as OPDA reductases, enzymes that are involved in JA synthesis in a susceptible cultivar.

Using three susceptible cultivars, we showed here that basal defense during the biotrophic phase of the infectious process varies between genotypes, and probably results from a given expression pattern of various genes rather than from important specific up-regulations. Nevertheless, in non-infectious context, the basal expression level of $P R 1$, gluc and aos was higher in both Premio and Altigo than in Alixan, with means of 10-fold for PR1 and gluc, and 4-fold for aos. Such a constitutive expression could participate to the natural basal resistance of Premio and Altigo expressed during the first steps of the biotrophic phase of fungal development.

\section{Wheat basal resistance levels differently affect symptom development and fungal} sporulation

The extent of symptom development and sporulation of Z. tritici have been shown to depend on the resistance level of the host (Cohen and Eyal, 1993; Kema et al., 1996; Duncan and Howard, 2000). The range of symptoms caused by the T01193 Z. tritici strain used in the present study on Alixan, Premio and Altigo wheat cultivars is in accordance with disease levels previously reported for these cultivars in field conditions. Indeed, resistance to STB was scored 4, 5.5 and 7 in Alixan, Premio and Altigo respectively, on a scale from 1 
(susceptible) to 9 (resistant), in 2009 field trials by the French technical institute ArvalisInstitut du végétal. Under semi-controlled conditions, Altigo exhibited at 21 dai the lowest level of diseased leaf area with both symptoms and pycnidia, thus confirming its highest resistance level against $Z$. tritici. Levels of symptoms and sporulation recorded on the most susceptible cultivar, Alixan, were both higher than in Altigo. Interestingly, the moderately resistant cultivar, Premio, showed a percentage of leaf area with symptoms close to that of the susceptible wheat cultivar Alixan, and a pycnidial density similar to that of the resistant cultivar Altigo. Our microscopic study highlighted the stages of fungal infectious process that were different between the three cultivars. The rate of stomatal penetration (PSS) was similar among the three cultivars, which exhibited the same frequency of colonized substomatal cavities (CS) at the histological level at 21 dai. At the macroscopic level, necrosis was reduced in Altigo in comparison to Alixan and Premio. This reduction of macroscopic symptoms suggests an alteration in the switch to the necrotrophic phase, which can not be related to the extent of host colonization. In addition, the percentage of penetrating spore (PS) is reduced in Altigo in comparison with Alixan and Premio. This suggests that defense mechanisms take place earlier in Altigo than in Premio and Alixan, delaying the switch to necrotrophic phase. Moreover, the proportion of CS bearing pycnidia (CSP) within the total CS was found to be lower in Altigo only, while at the macroscopic level, both Premio and Altigo displayed similar and low sporulation levels. At the macroscopic level, only mature pycnidia are visible and could be considered in the assessment of the sporulation, whereas at the microscopic level, all pycnidia - young and mature - are visible and accountable. It can be suggested that late defense mechanisms in Altigo inhibit or delay both necrosis and pycnidium formation, whereas in Premio, they only slow down pycnidium development in substomatal cavities. This point is also interesting since at the field level, the reduction of sporulation contributes to reduce spore dissemination. All together, these results suggest that 
the distinct basal resistance levels of wheat cultivars against Z. tritici may also depend on defense mechanisms expressed lately, as described by Rudd et al. (2015), and involved either in symptom or in sporulation inhibitions.

It is important to underline that defense mechanisms involved in wheat resistance also take place during the transition to the necrotrophic phase and during symptoms expression. Rudd et al (2015) described a peak in wheat defense activation during the fungal necrotrophic colonization phase. In parallel, fungal genes were highly expressed, such as those encoding for secreted CWDEs, including first proteases, followed by carbohydrate degrading enzymes (CAZymes). It has been previously shown that the activity of CWDEs was associated with $Z$. tritici pathogenicity and impacted the disease level of wheat (Douaiher et al., 2007; Siah et al., 2010; Tian et al., 2009). In the present work, we highlighted significantly higher levels of $\beta$-1,4- endoxylanase, $\beta$-1,4- endoglucanase and protease activities in the three cultivars from 17 dai, date from which symptoms can be observed (data not shown). At 21 dai, they reached their highest activity levels in Alixan and were associated with the highest pycnidium density. Therefore, $\beta$-1,4-endoxylanase, $\beta$-1,4- endoglucanase and protease activities seem to correlate with the degree of fungal sporulation, suggesting their involvement in providing the fungus nutrients for asexual reproduction. These observations confirm results of Siah et al. (2010) and Tian et al. (2009), where CWDEs produced by Z. tritici were associated with the sporulation level of the fungus, and negatively correlated with the resistance level of wheat.

In conclusion, the occurrence of susceptible wheat response to Z. tritici infection is clearly cultivar-dependent However, an important and early expression of defense-related genes is not associated with a reduction of necrosis development when comparing susceptible or partially resistant wheat cultivars, suggesting that the pathogen manipulates defense gene 
expression in susceptible cultivars during the first steps of infectious process in order to promote disease development. A similar mesophyll colonization that is followed by a delayed necrosis development and/or delayed sporulation of $Z$. tritici suggests a distinct regulation of wheat defense genes in the three susceptible cultivars at the transition phase to necrotrophic lifestyle. Basal levels of expression of genes encoding for QDR-associated genes are likely to be more accurate markers for the expression and the selection of partial but more durable resistance to $Z$. tritici in wheat.

\section{References.}

Adhikari, T.B., Balaji, B., Breeden, J., and Goodwin, S.B. (2007). Resistance of wheat to Mycosphaerella graminicola involves early and late peaks of gene expression. Physiol. Mol. Plant Pathol. 71, 55-68.

Båga, M., Chibbar, R.N., and Kartha, K.K. (1995). Molecular cloning and expression analysis of peroxidase genes from wheat. Plant Mol. Biol. 29, 647-662.

Bollina, V., Kushalappa, A.C., Choo, T.M., Dion, Y., and Rioux, S. (2011). Identification of metabolites related to mechanisms of resistance in barley against Fusarium graminearum, based on mass spectrometry. Plant Mol. Biol. 77, 355-370.

Bolwell, G.P., and Wojtaszek, P. (1997). Mechanisms for the generation of reactive oxygen species in plant defence - a broad perspective. Physiol. Mol. Plant Pathol. 51, 347-366.

Brading, P.A., Verstappen, E.C.P., Kema, G.H.J., and Brown, J.K.M. (2002). A gene-forgene relationship between wheat and Mycosphaerella graminicola, the septoria tritici blotch pathogen. Phytopathology 92, 439-445. 
Chartrain, L., Brading, P.A., Widdowson, J.P., and Brown, J.K.M. (2004b). Partial resistance to septoria tritici blotch ( Mycosphaerella graminicola) in wheat cultivars Arina and Riband. Phytopathology 94, 497-504.

Cohen, L., and Eyal, Z. (1993). The histology of processes associated with the infection of resistant and susceptible wheat cultivars with Septoria tritici. Plant Pathol. 42, 737-743.

Creelman, R.A., and Mullet, J.E. (1997). Biosynthesis and action of jasmonates in plants. Annu. Rev. Plant Physiol. Plant Mol. Biol. 48, 355-381.

Diani, Z., El-Mostafa, O., Aissam, S., Hsissou, D., and El-Modafar, C. (2009). Induction of early oxidative events in soft wheat leaves inoculated with Septoria tritici and their relationship to resistance of Moroccan cultivars. Int. J. Agric. Biol. Pak.

Douaiher, M.-N., Nowak, E., Durand, R., Halama, P., and Reignault, P. (2007). Correlative analysis of Mycosphaerella graminicola pathogenicity and cell wall-degrading enzymes produced in vitro: the importance of xylanase and polygalacturonase. Plant Pathol. 56, 79-86.

Duncan, K.E., and Howard, R.J. (2000). Cytological analysis of wheat infection by the leaf blotch pathogen Mycosphaerella graminicola. Mycol. Res. 104, 1074-1082.

Fazeli, A., and Jelodar, N.B. (2012). Development of DNA Microarray Technique to Evaluation of transcriptional responses of wheat to Mycosphaerella graminicolla (septoria tritici). J. Plant Pathol. Microbiol. 1.

Gao, L., Wang, S., Li, X.-Y., Wei, X.-J., Zhang, Y.-J., Wang, H.-Y., and Liu, D.-Q. (2015). Expression and functional analysis of a Pathogenesis-Related Protein 1 Gene, TcLr19PR1, involved in wheat resistance against leaf rust fungus. Plant Mol. Biol. Report. 33, 797-805. 
Goodwin, S.B., Ben M'Barek, S., Dhillon, B., Wittenberg, A.H.J., Crane, C.F., Hane, J.K., Foster, A.J., Van der Lee, T.A.J., Grimwood, J., Aerts, A., et al. (2011). Finished genome of the fungal wheat pathogen Mycosphaerella graminicola reveals dispensome structure, chromosome plasticity, and stealth pathogenesis. PLoS Genet 7, e1002070.

Hammond-Kosack, K.E., and Rudd, J.J. (2008). Plant resistance signalling hijacked by a necrotrophic fungal pathogen. Plant Signal. Behav. 3, 993-995.

Hellweg, M. (2003). Molecular biological and biochemical studies of proteolytic enzymes of the cereal pathogen Fusarium graminearum. PhD thesis, University of Münster, Deutschland, 240 pages.

Kema, G.H.J., Yu, D., Rijkenberg, F.H.J., Shaw, M.W., and Baayen, R.P. (1996). Histology of the pathogenesis of Mycosphaerella graminicola in wheat. Phytopathology 86, 777-786. Keon, J., Rudd, J.J., Antoniw, J., Skinner, W., Hargreaves, J., and Hammond-Kosack, K. (2005). Metabolic and stress adaptation by Mycosphaerella graminicola during sporulation in its host revealed through microarray transcription profiling. Mol. Plant Pathol. 6, 527-540.

Lee, W.-S., Rudd, J.J., Hammond-Kosack, K.E., and Kanyuka, K. (2014). Mycosphaerella graminicola LysM effector-mediated stealth pathogenesis subverts recognition through both CERK1 and CEBiP homologues in wheat. Mol. Plant. Microbe Interact. 27, 236-243.

Livak, K.J., and Schmittgen, T.D. (2001). Analysis of relative gene expression data using real-time quantitative PCR and the 2- $\Delta \Delta \mathrm{CT}$ method. Methods 25, 402-408.

Marshall, R., Kombrink, A., Motteram, J., Loza-Reyes, E., Lucas, J., Hammond-Kosack, K.E., Thomma, B.P.H.J., and Rudd, J.J. (2011). Analysis of two in planta expressed LysM effector homologs from the fungus Mycosphaerella graminicola reveals novel functional properties and varying contributions to virulence on wheat. Plant Physiol. 156, 756-769. 
Mitchell, H.J., Hall, J.L., and Barber, M.S. (1994). Elicitor-induced cinnamyl alcohol dehydrogenase activity in lignifying wheat (Triticum aestivum L.) Leaves. Plant Physiol. 104, $551-556$.

O’Brien, J.A., Daudi, A., Butt, V.S., and Bolwell, G.P. (2012). Reactive oxygen species and their role in plant defence and cell wall metabolism. Planta 236, 765-779.

Orton, E.S., Deller, S., and Brown, J.K.M. (2011). Mycosphaerella graminicola: from genomics to disease control. Mol. Plant Pathol. 12, 413-424.

Passardi, F., Cosio, C., Penel, C., and Dunand, C. (2005). Peroxidases have more functions than a Swiss army knife. Plant Cell Rep. 24, 255-265.

Randoux, B., Renard, D., Nowak, E., Sanssené, J., Courtois, J., Durand, R., and Reignault, P. (2006). Inhibition of Blumeria graminis f. sp. tritici germination and partial enhancement of wheat defenses by Milsana. Phytopathology 96, 1278-1286.

Rudd, J.J. (2015). Previous bottlenecks and future solutions to dissecting the Zymoseptoria tritici-wheat host-pathogen interaction. Fungal Genet. Biol. 79, 24-28.

Rudd, J.J., Keon, J., and Hammond-Kosack, K.E. (2008). The wheat mitogen-activated protein kinases TaMPK3 and TaMPK6 are differentially regulated at multiple levels during compatible disease interactions with Mycosphaerella graminicola. Plant Physiol. 147, 802815.

Scholtz, J.J., and Visser, B. (2013). Reference gene selection for qPCR gene expression analysis of rust-infected wheat. Physiol. Mol. Plant Pathol. 81, 22-25.

Selim, S., Roisin-Fichter, C., Andry, J.-B., Bogdanow, B., and Sambou, R. (2014). Real-time PCR to study the effect of timing and persistence of fungicide application and wheat varietal 
resistance on Mycosphaerella graminicola and its sterol 14 $\alpha$-demethylation-inhibitorresistant genotypes. Pest Manag. Sci. 70, 60-69.

Shetty, N.P., Kristensen, B.K., Newman, M.-A., Møller, K., Gregersen, P.L., and Jørgensen, H.J.L. (2003). Association of hydrogen peroxide with restriction of Septoria tritici in resistant wheat. Physiol. Mol. Plant Pathol. 62, 333-346.

Shetty, N.P., Mehrabi, R., Lütken, H., Haldrup, A., Kema, G.H.J., Collinge, D.B., and Jørgensen, H.J.L. (2007). Role of hydrogen peroxide during the interaction between the hemibiotrophic fungal pathogen Septoria tritici and wheat. New Phytol. 174, 637-647.

Shetty, N.P., Jensen, J.D., Knudsen, A., Finnie, C., Geshi, N., Blennow, A., Collinge, D.B., and Jørgensen, H.J.L. (2009). Effects of $\beta$-1,3-glucan from Septoria tritici on structural defence responses in wheat. J. Exp. Bot. 60, 4287-4300.

Siah, A., Deweer, C., Duyme, F., Sanssené, J., Durand, R., Halama, P., and Reignault, P. (2010). Correlation of in planta endo-beta-1,4-xylanase activity with the necrotrophic phase of the hemibiotrophic fungus Mycosphaerella graminicola. Plant Pathol. 59, 661-670.

Simón, M.R., Cordo, C.A., Castillo, N.S., Struik, P.C., and Börner, A. (2012). Population structure of Mycosphaerella graminicola and location of genes for resistance to the pathogen: recent advances in Argentina. Int. J. Agron. 2012, e680275.

Stotz, H.U., Mitrousia, G.K., de Wit, P.J.G.M., and Fitt, B.D.L. Effector-triggered defence against apoplastic fungal pathogens. Trends Plant Sci.

Tian, S.M., Weinert, J., and Zhao, Q.H. (2009). Correlation between cell wall-degrading enzymes in wheat leaves infected by Septoria tritici and disease severity. Can. J. Plant Pathol. $31,387-392$. 
Wu, J.-S., Chong, K., Xu, Y.-Y., and Tan, K.-H. (2004). Cloning and characteristics of an allene oxide synthase gene (TaAOS) of winter wheat. Zhi Wu Sheng Li Yu Fen Zi Sheng Wu Xue Xue Bao 30, 413-420.

Yang, F., Melo-Braga, M.N., Larsen, M.R., Joergensen, H.J.L., and Palmisano, G. (2013). Battle through signaling between wheat and the fungal pathogen Septoria tritici revealed by proteomics and phosphoproteomics. Mol. Cell. Proteomics mcp.M113.027532.

\section{Figures legends}

Figure 1. Disease level induced by the T01193 Z. tritici strain on Alixan, Premio and Altigo wheat cultivars. Leaf area with symptoms (a) was evaluated at 21 dai by noting the percentage of third leaf area covered by symptoms (chlorosis and necrosis) on 20 plants. The sporulation level (b) was estimated by noting the pycnidial density on a scale from 0 (low density) to 5 (high density). Data represent means of two independent experiments. Values tagged with the same letter are not significantly different using the Tukey test at $P \leq 0.05$.

Figure 2. Time course of fungal $\beta$-1,4-endoxylanase (a), $\beta$-1,4-endoglucanase (b) and protease (c) activities in Alixan, Premio and Altigo non-inoculated (nI) and inoculated (I) with the T01193 Z. tritici strain. Data represent means of two independent experiments. For each time point, means tagged with the same letter are not significantly different using the Tukey test at $P \leq 0.05$. 
Figure 3. Relative expression of pox2 (peroxidase) and oxo (oxalate oxidase) wheat genes in leaves of Alixan, Premio and Altigo inoculated with the Z. tritici strain T01193 (I) compared to their respective non-inoculated control leaves (represented by a line at expression level=1). Ratios (Inoculated/non inoculated) were estimated at 3, 6, 12, 24, 72 and 96 hai. Means tagged with the same letter are not significantly different, means with asterisk are significantly different from non inoculated control for each time point using Tukey test at $P \leq$ 0.05 .

Figure 4. Relative expression of lox (lipoxygenase) and aos (allen oxide synthase) wheat genes in leaves of Alixan, Premio and Altigo inoculated with the Z. tritici strain T01193 (I) compared to their respective non inoculated control leaves (represented by a line at expression level=1). Ratios (Inoculated/non inoculated) were estimated at 3, 6, 12, 24, 72 and 96 hai. Means tagged with the same letter are not significantly different, means with asterisk are significantly different with non inoculated control for each time point using Tukey test at $P \leq 0.05$.

Figure 5. Relative expression of pal (phenylalanine ammonia lyase) and chs (chalcone synthase) wheat genes in leaves of Alixan, Premio and Altigo inoculated with the Z. tritici strain T01193 (I) compared to their respective non-inoculated control leaves (represented by a line at expression level=1). Values correspond to the average of data from three technical repetitions from 2 biological samples. Ratios (Inoculated/non inoculated) were estimated at 3, 6, 12, 24, 72 and 96 hai. Means tagged with the same letter are not significantly different, means with asterisk are significantly different with non inoculated control for each time point using Tukey test at $P \leq 0.05$. 
Figure 6. Relative expression of $p r l$, chit2 and gluc wheat genes in leaves of Alixan, Premio and Altigo inoculated with the Z. tritici strain T01193 (I) compared to their respective non inoculated control leaves (represented by a line at expression level=1). Values correspond to the average of data from three technical repetitions from 2 biological samples. Ratios (Inoculated/non inoculated) were estimated at 3, 6, 12, 24, 72 and 96 hai. Means tagged with the same letter are not significantly different, means with asterisk are significantly different with non inoculated control for each time point using Tukey test at $P \leq 0.05$.

Table 1. Selected genes, their accession numbers (GenBank) and their corresponding primer sets, used for the analysis of transcript profiles from wheat leaves.

\begin{tabular}{|c|c|c|c|c|c|c|}
\hline Name & $\begin{array}{c}\text { GenBank } \\
\text { Accession } \\
n^{\circ}\end{array}$ & Primer Foward 5'-3' & $\begin{array}{l}\mathrm{Tm} \\
\left({ }^{\circ} \mathrm{C}\right)\end{array}$ & Primer Reverse 5'-3' & $\begin{array}{l}\mathrm{Tm} \\
\left({ }^{\circ} \mathrm{C}\right)\end{array}$ & $\begin{array}{l}\text { Amplicon } \\
\text { lengh (pb) }\end{array}$ \\
\hline tub6 & U76897 & CTGCCTCCAAGGTTTCCAAGTA & 59.2 & GTGTCCATCCCGGAACCA & 59.7 & 53 \\
\hline gapdh & AF251217 & AAGGGCATTTTGGGTTACGTT & 58.4 & СCTGTTGTCACCCTGGAAGTC & 58.1 & 53 \\
\hline pr1 & HQ848391 & CATGCACCTTCGTATGCCTAACT & 58.9 & TGGCTAATTACGGCATTCCTTT & 59.4 & 52 \\
\hline chit.2 & AB029935 & GGGTGGACCTGCTGAACAAT & 58.4 & AGAACCATATCGCCGTCTTGA & 58.3 & 75 \\
\hline gluc. & DQ090946 & TCCTGGGTTCAGAACAATGTCC & 59.8 & TTGATGTTGACAGCCGGGTAGT & 60.4 & 50 \\
\hline lox & U32428 & GGGCACCAAGGAGTACAAGGA & 59.9 & GCTCGTGATGGTGTGGATGA & 59.1 & 66 \\
\hline aos & AY196004 & AGGCCGGAGAGAAGTTCCAC & 59.3 & CCGACTTGGTCAGCTCCATC & 59.2 & 119 \\
\hline pal & AY005474 & GTCGATTGAGCGTGAGATCAAC & 58.0 & CACGGGAGACGTCGATGAG & 59.0 & 59 \\
\hline chs & AY286097 & GCGCCTGCGTACTCTTCATC & 60.0 & CCTCGGCGGAGCGTTT & 59.0 & 51 \\
\hline pox2 & X85228 & TGCTTTGTCCAAGGCTGTGA & 59.0 & GACCCGCGTTTTGTTCCA & 59.1 & 61 \\
\hline oxo & AJ556991 & GCCAGAACCCCGGTATCG & 60.0 & GGTGGGTTGGAGCTGAAGAG & 58.0 & 55 \\
\hline
\end{tabular}


Table 2. Percentages of five distinct infection process events on the wheat cultivars Alixan, Premio and Altigo inoculated with the T01193 Z. tritici strain. (GS), percentages of germinated spores; (PS), spores with penetrating germ tube ; (PSS), within PS, spores with germ tube penetrating through stomata ; (CS), colonized substomatal cavities; (CSP), within CS, colonized substomatal cavities bearing pycnidia. Data represent mean of two independent experiments; three leaf segments from each cultivar were observed per experiment. For each cultivar, means tagged with the same letter are not significantly different using the Tukey test at $P \leq 0.05$.

\begin{tabular}{|c|c|c|c|c|}
\hline & \multirow{2}{*}{$\begin{array}{l}\text { 1dai } \\
\% \text { GS }\end{array}$} & \multirow{2}{*}{$\begin{array}{c}\text { 5dai } \\
\% \text { PS } \% \text { PSS }\end{array}$} & \multicolumn{2}{|c|}{ 21dai } \\
\hline & & & $\%$ CS & $\%$ CSP \\
\hline Alixan & $68.1 \mathrm{a}$ & 52.9 a $\quad 28.2 \mathrm{a}$ & $79.2 \mathrm{a}$ & $19.4 \mathrm{a}$ \\
\hline Premio & $71.5 \mathrm{a}$ & $55.2 \mathrm{a} \quad 24.7 \mathrm{a}$ & $72.0 \mathrm{a}$ & $23.9 \mathrm{a}$ \\
\hline Altigo & $73.3 \mathrm{a}$ & $29.3 \mathrm{~b} \quad 24.2 \mathrm{a}$ & $73.0 \mathrm{a}$ & $5.2 \mathrm{~b}$ \\
\hline
\end{tabular}

Table 3. Relative expression of prl, chit2, gluc, lox, aos, pal, chs, pox2 and oxo genes in non-inoculated leaves of Premio and Altigo compared to Alixan. For each gene, means in bold are significantly different from Alixan using the Tukey test at $P \leq 0.05$. The expression level of target gene in Alixan used for relative expression was considered to be 1 .

\begin{tabular}{lrrrrrrrrr}
\hline & \multicolumn{1}{c}{ pr1 } & \multicolumn{1}{c}{ chit2 } & \multicolumn{1}{c}{ gluc } & \multicolumn{1}{c}{ lox } & \multicolumn{1}{c}{ aos } & pal & chs & pox2 & oxo \\
\hline Alixan & $1.0 \mathrm{a}$ & $1.0 \mathrm{a}$ & $1.0 \mathrm{a}$ & $1.0 \mathrm{a}$ & $1.0 \mathrm{a}$ & $1.0 \mathrm{a}$ & $1.0 \mathrm{a}$ & $1.0 \mathrm{a}$ & $1.0 \mathrm{a}$ \\
Premio & $\mathbf{1 0 . 9} \mathbf{b}$ & $\mathbf{2 . 1} \mathbf{b}$ & $\mathbf{9 . 9} \mathbf{b}$ & $\mathbf{1 . 5} \mathbf{b}$ & $\mathbf{3 . 6} \mathbf{b}$ & $\mathbf{2 . 7} \mathbf{b}$ & $\mathbf{0 . 6} \mathbf{b}$ & $\mathbf{2 . 1} \mathbf{b}$ & $\mathbf{5 . 1} \mathbf{b}$ \\
Altigo & $\mathbf{9 . 1} \mathbf{b}$ & $1.4 \mathrm{a}$ & $\mathbf{1 0 . 8} \mathbf{b}$ & $1.2 \mathrm{ab}$ & $\mathbf{4 . 5} \mathbf{b}$ & $1.4 \mathrm{a}$ & $\mathbf{0 . 6} \mathbf{b}$ & $0.8 \mathrm{a}$ & $1.5 \mathrm{a}$ \\
\hline
\end{tabular}



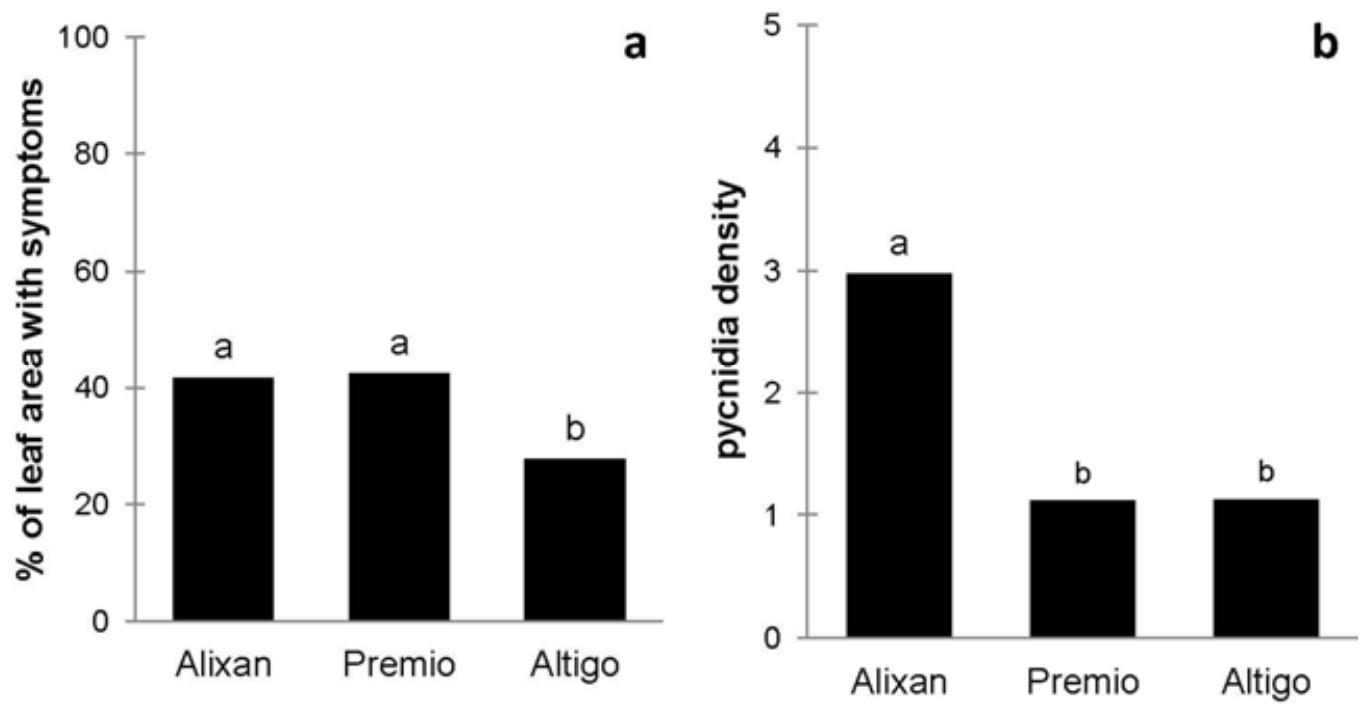

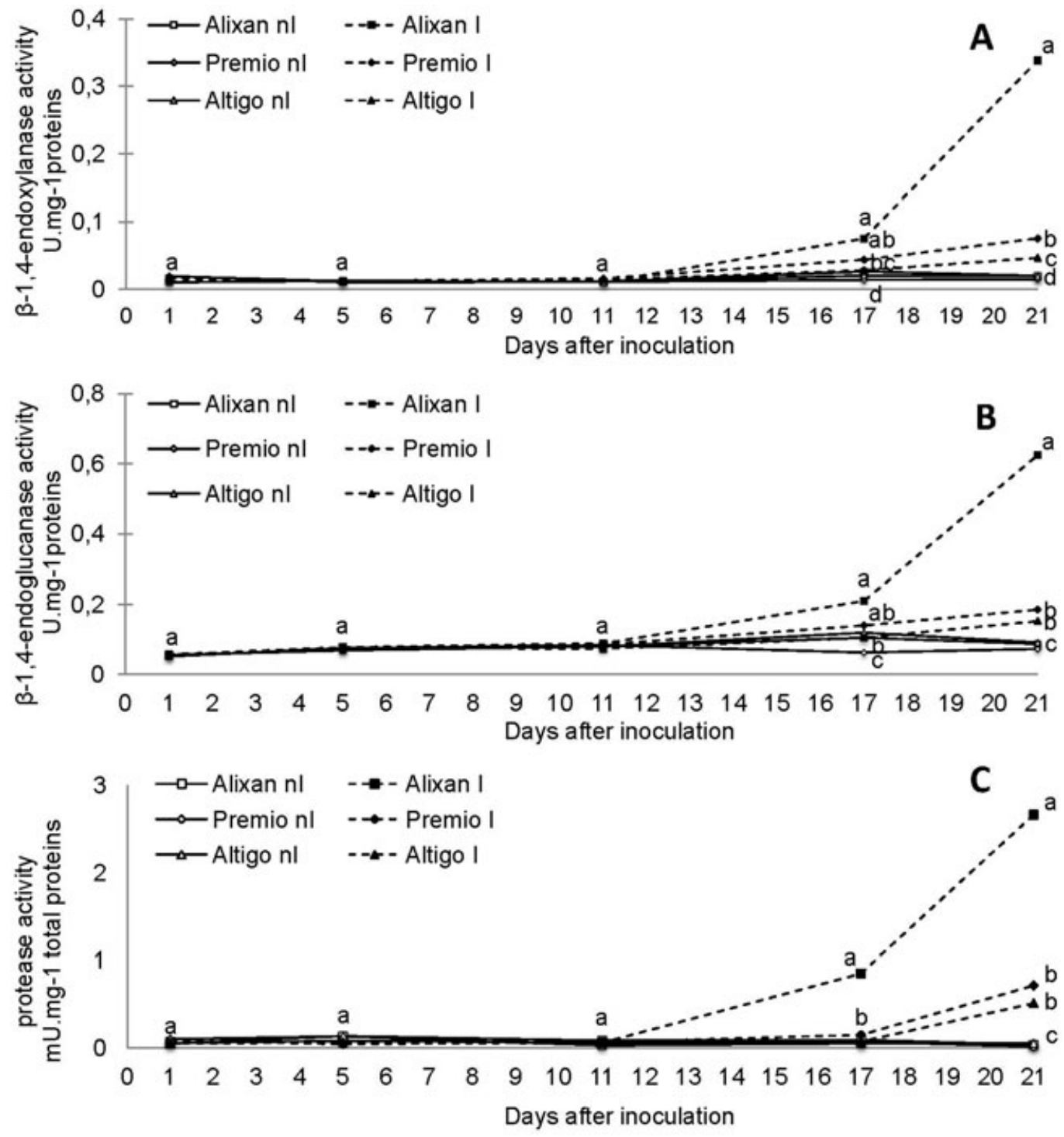

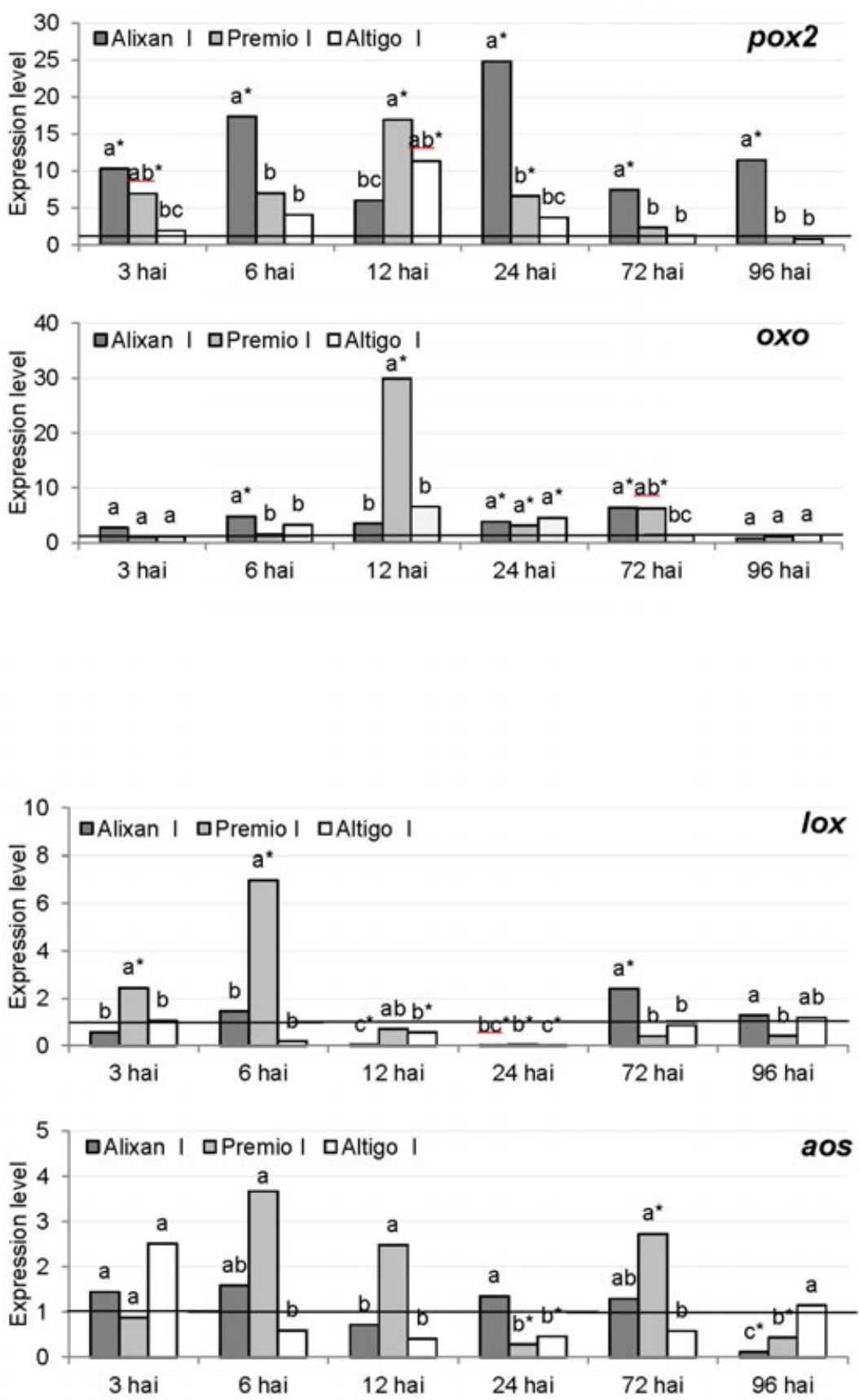

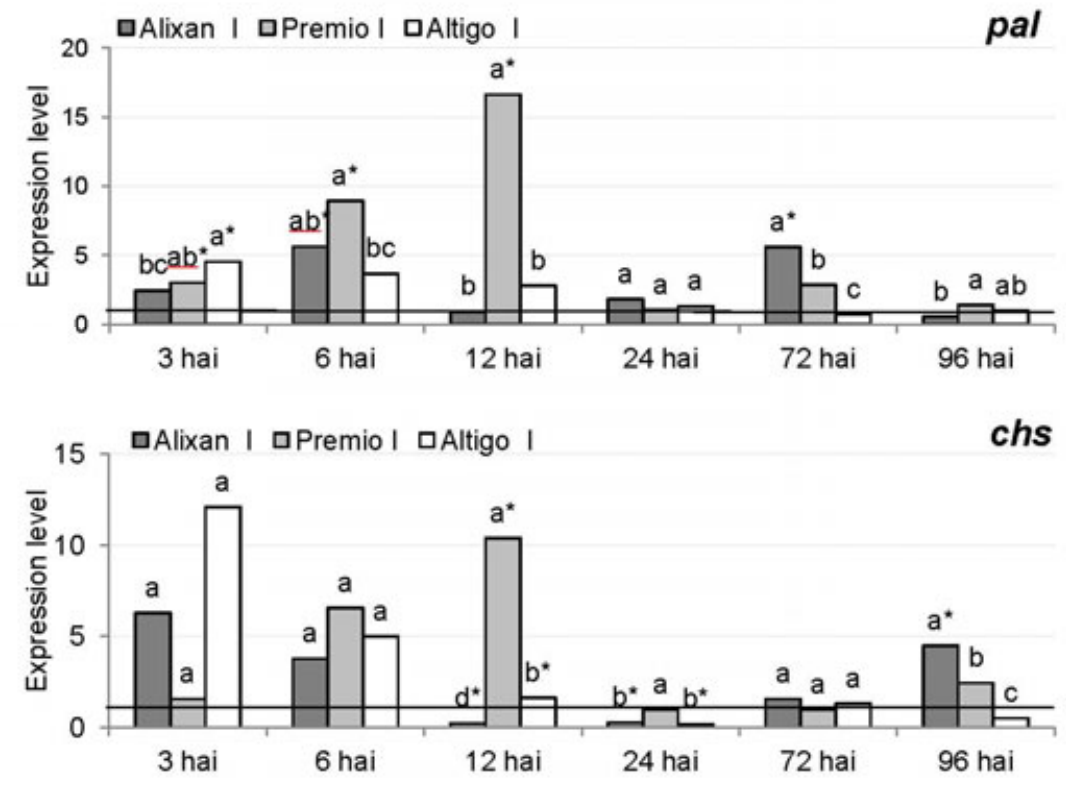

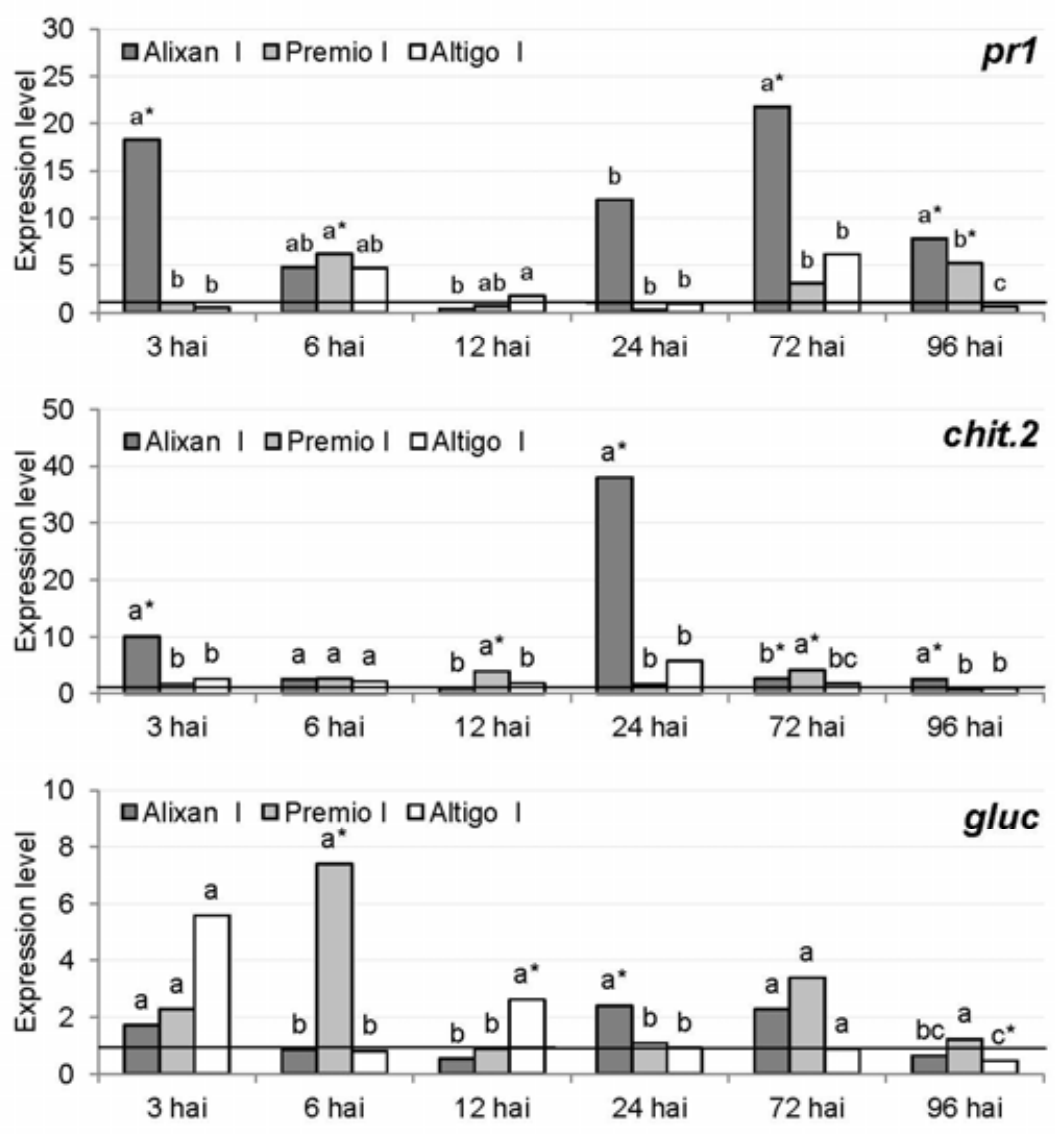